\title{
WordUp: An App that Teaches English Words through Extensive Exposure to Authentic Materials
}

\author{
Musa Nushi ${ }^{\mathrm{a}}$, Alireza Aghaei ${ }^{\mathrm{a}}$, and Maryam Roshanbin ${ }^{\mathrm{b}}$ \\ ${ }^{a}$ Shahid Beheshti University; ${ }^{b}$ Iran University of Science and Technology
}

\begin{abstract}
This paper reviews WordUp, a mobile application which fosters English vocabulary learning through exposure to new words in authentic and engaging contexts such as excerpts of movies, songs, and news programme. The samples of use are introduced after the definition of the target words have been provided in both the learners' first language and English. In this review, the advantage of extensive exposure to authentic use of the target words will be discussed. Moreover, some of the app's shortcomings such as its unsuitability for beginner learners and insufficient tasks to improve the users' production of the learned vocabulary will be highlighted. WordUp is recommended for learners above level A1 The Common European Framework of Reference for Languages (CEFR) who wish to learn the appropriate application of the learned material through authentic input.
\end{abstract}

Keywords: Applications, mobile learning, second language, technology, vocabulary, WordUp

\section{Introduction}

Developing the depth and breadth of learners' vocabulary has always been high on second language (L2) teachers' agenda (Nushi \& Jenabzadeh, 2016). This concern is understandable given the importance of vocabulary in language learning. McCarthy (1990, p. 8) noted that "no matter how well the student learns grammar, no matter how successfully the sounds of L2 are mastered, without words to express a wide range of meanings, communication in an L2 just cannot happen in any meaningful way." Lewis (1993) goes even further, contending that "lexis is the core or heart of language" (p. 89). Learning vocabulary in another language is not without its own challenges and numerous studies have been conducted to facilitate this process, mainly through equipping learners with various vocabulary learning and retention strategies (Fan, 2020; Mizumoto \& Takeuchi, 2009; Moir \& Nation, 2002; Taka, 2008). Such an extensive scholarly enterprise seems warranted given the fact that acquiring vocabulary knowledge is a multi-faceted, experience-based process. Acknowledging that fact, Zhang (2020, p. 1) stated that "lexical knowledge is a multi-faceted and complex construct with multiple cognitive and linguistic skills involved." Nation (2013) argued that knowing a word includes knowing its form, meaning and use. More specifically, form refers to knowledge of the written and spoken representation of a word. Meaning entails 
knowledge of the denotative (i.e., literal or conceptual) and connotative (i.e., figurative or associative) meanings of a word. Finally, use refers to the understanding of how a word should be used in linguistic and social contexts. Schmitt (2000) added that words can have different meanings in different contexts and lexical instruction needs to be comprehensive.

Teaching vocabulary, in comparison to other components of language instruction, has not received the attention it merits (Block \& Fitzgerald, 2006; Cunningham, 2009). Research has also demonstrated that conventional vocabulary activities such as looking up the words and memorising their definition do not effectively help vocabulary learning (Cunningham, 2009). Advancements in technology, however, have provided L2 teachers and learners with many opportunities which can effectively increase the students' vocabulary knowledge (Lin \& Lin, 2019). Yet, there is still a need for more research regarding the use of these technological innovations to extend and enhance vocabulary teaching and learning practices. One of the ways that technology can help vocabulary instruction is through exposing learners to large amounts of authentic reading materials. Nunan (1988, p. 99) defined authentic materials as those "which have been produced for purposes other than to teach language," In other words, authentic materials involve the natural use of spoken or written language for communication in the native speaker context. Although researchers have not reached a consensus regarding the use of authentic materials (e.g., YouTube videos, TV series and programmes, songs, movies, books, magazines, podcasts) for L2 teaching and learning purposes (see Gilmore, 2007 for a review), there are many studies showing that such materials can prove beneficial to L2 learners by not only exposing them to real-life examples of language use and thus preparing them for real world communication, but also raising their motivation to take part in classroom activities (Namaziandost et al., 2021; Peacock, 1997).

The present article reviews a mobile application that aims to teach leaners new English words and improve their vocabulary in the language through a variety of authentic examples of spoken English for each word from movie clips, songs and quotes. The review explores the possibilities the app can offer for learning English words, and provides a number of suggestions that the app designers can use to improve the app and make learning vocabulary a more fruitful experience for learners.

\section{Description}

WordUp can be downloaded from http://www.wordupapp.co, which redirects the users to App Store for iOS devices, Google Play for Android devices, and Microsoft for Windows devices. This application starts by asking the learners about their age, approximate language proficiency level, and preferred accent (Figure 1a-c).

Moreover, it gives the learners a placement test which indicates which position on the 25,000-word list best fits their vocabulary knowledge (Figure 2a). After they have taken the test and set a reminder for their daily vocabulary exercise (Figure 2b), every day they will take a similar test to discover more words, among the 1,000 words appropriate for their level, to learn. According to their usefulness, 
a

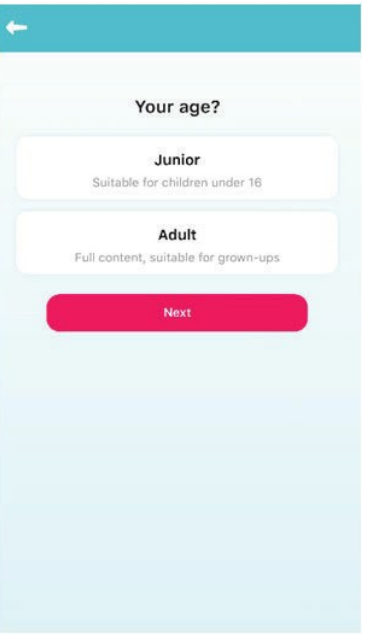

b

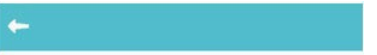

Your Level?

In your opinion, what is your level?

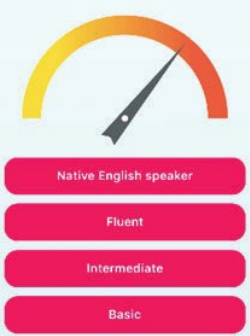

c

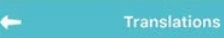

Preferred Accent

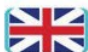

\section{Next}

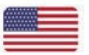

Figure 1. (a-c) The First Three Stages WordUp Users Go Through to Adjust the Application to Their Needs.

a

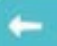

Recommended learning range:

$$
\text { 5,001-6,000 }
$$

Discover $~ 195$ words to learn from the range $5,001-6,000$ of the most frequently used English words.

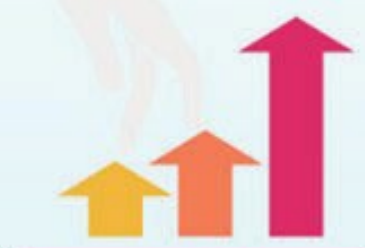

Discover them b

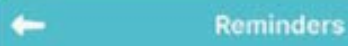

\section{Best times to practice?}

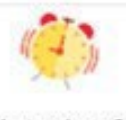

Just woke up?

Around breakfast?

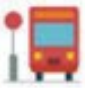

Way to work or school?

Around lunchtime?

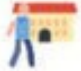

Way back home?

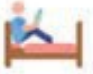

In bed?

Dont ask again

Figure 2. (a, b) Determining the Users' Appropriate Level and Reminding Schedule. 
the words are categorised into 25 groups of 1,000 words, ranked from the first most useful and frequently used thousand words to the 25 th thousand one. Facing a new word, the users will see three options that WordUp offers (Figure 3a). They can confirm that they know the word, confirm that they do not know the word and would like to learn it, or ask the application to test them if they are not sure about the word's meaning. When the learners start learning a word, a dictionary entry containing the word's definition, pronunciation, part of speech, first language (L1) equivalence, and some examples appear (Figure $3 b$ ).

What makes WordUp special, however, is the extensive list of authentic examples which are found using search engines and artificial intelligence technologies. This list is shown after the dictionary entry and the users are able to find and include quotations, excerpts of TV series, movies, news programmes and songs in these lists (Figure 4). The app developers claim that they "use a combination of well-grounded sources such as Oxford" to create their own list (WordUp Team, personal communication, September 7, 2021). This extensive list of various authentic examples will help the learners engage in the process of vocabulary learning and find opportunities to enjoy learning new words while they read, watch, and listen to interesting texts and other forms of media. The online corpora can also help learners become independent learners (see Giampieri, 2019;

a

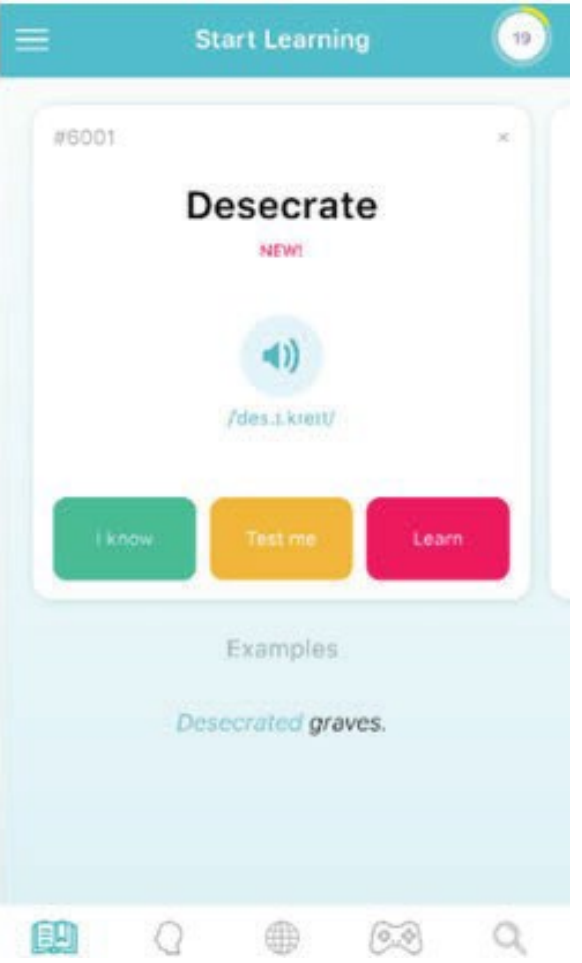

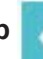

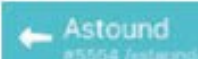

verb Astound somebody

‡ Synonyms: Astonish, surprise, startle, amaze, stun, take somebody aback

To surprise or shock somebody very much His arrogance astounded her.

She was astounded by his arrogance

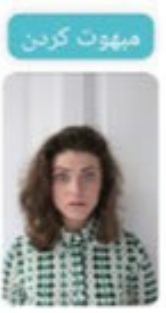

Examples

Figure 3. $(a, b)$ Three Options Offered to the Users When They Face a Word and the Display of Each Word's Dictionary Entry. 

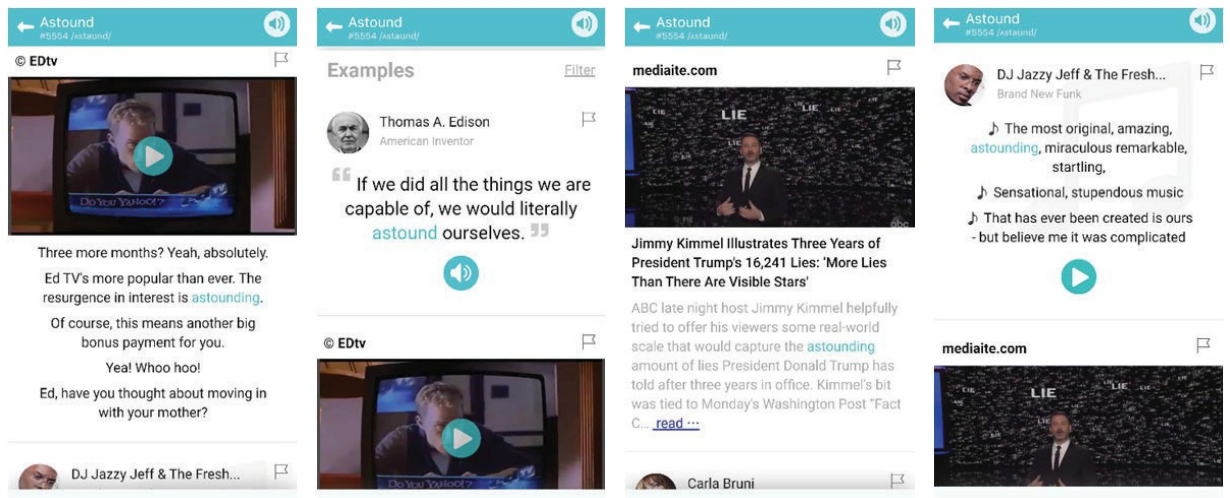

Figure 4. Authentic Examples of the Words Used in Several Contexts.

Mills, 2000; and Römer, 2011 for the use of Web-based corpora for second language teaching and learning). It also seems that WordUp uses spaced repetition to make sure users remember words in the long-term. Spaced repetition is an effective vocabulary learning technique that involves reviewing and recalling previously learned material at gradually increasing intervals until the information is satisfactorily learned (Nakata, 2015).

After the users have worked on the word and its authentic use in different contexts, WordUp will ask them the meaning of that word the next day. Provided that they answer correctly, it will ask them whether they remember that word after 3 days, a week, a month, 3 months, and a year. Whenever the users forget the word during the process, the reminding sequence will start all over again.

Although users can access many options freely, WordUp has some in-app purchase options that give students access to even more. There are two types of accounts which can be purchased, namely "essential" and "pro." The essential account, costing \$11.99 per year or \$39 for an unlimited period of time, cancels the advertisements (ads) which frequently interrupt the lessons. The pro subscription, however, gives users access to several more options. Costing \$59 per a year and $\$ 99$ for a lifetime, the pro account not only removes all the ads, but also enables access to vocabulary games, categorised words based on their topics, examspecific words, idioms and phrases, and limitless examples.

\section{Evaluation}

WordUp has the potential to make a great contribution to the students' vocabulary learning and introduces an interesting and mesmerising way to the users to enhance their vocabulary size without the need of teachers and classrooms; hence, one can conclude that WordUp is capable of fostering learner autonomy as well. However, this is no more than a claim and research should indicate its correctness. Further research can also aim at answering these questions: Does WordUp result in enhancing the lexical knowledge of students at all levels? Do learners make use of all the options provided by WordUp or suffice to the L1 equivalences? How well 
can the students use the learned words in their productive skills? How can teachers take advantage of such technology to students' benefit? What are students and teachers' attitude toward using this app? Does such technology align with flipped classroom principals which will lead into the new classroom methodologies such as the Dogme ELT approach (Thornbury, 2000)?

WordUp has a significant affordance for English as a foreign language (EFL) speakers all over the world since it provides the learners with not only the English definition of the words and authentic instances of their use in English, but also the words' translation in the students' L1. WordUp supports a wide range of languages as the students' L1; thus, learners with lower levels of language proficiency can benefit from the equivalences of the vocabulary in their L1, if needed. Another positive feature of this app is the variety in the authentic examples it presents, which turns learning into an amusing experience for learners with different tastes and learning styles.

Although the advantages in using WordUp abound, there are some drawbacks to this app as well. It was mentioned earlier that WordUp supplies the learners with the translation of the new words. The L1 equivalences, however, seem to be borrowed from online dictionaries, and are not level-appropriate for learners with different levels of language proficiency. Moreover, some words have more than one part of speech and this app does not provide the users with L1 equivalences for more than one part of speech in most cases. The same problem occurs for words with different meanings. Besides, WordUp mentions idioms in which the words are used, while no L1 equivalence for those idioms are provided. Another noteworthy criticism is against the way WordUp chooses examples to be presented to the app users; thus, there are some issues that need to be addressed by the app developers to make the examples more efficient. Firstly, some quotations in which the words are mentioned are difficult to make sense of without the context in which they were originally used. Furthermore, some quotations are in the form of dependent clauses and the rest of the utterance seems to be missing, which makes understanding the examples quite difficult for the students. Secondly, the excerpts containing the to-be-learned word might include vocabularies that are unlikely to exist in the learners' lexical knowledge; hence, the users might find it difficult to comprehend the texts and ignore those examples. This lack of curation for the language level required to understand the examples is ubiquitous in WordUp. In addition, every word has a meaning sense, regarding its connotation and denotation, which is of great importance when it comes to learning and using that word. WordUp seems not to have taken this fact into account and the examples provided after each word do not specify the meaning sense of the words. This lack or precaution has led to the absence of sufficient examples for different meanings and parts of speech of one word. Finally, since WordUp uses online sources to find examples and instances of the words, users who do not have constant network connection will be deprived of exposure to the authentic use of the words.

As mentioned earlier, one of the most significant features of WordUp is supplying the learners with authentic language. Literature ascertains that exposure to authentic language input is highly advantageous for language learners (Brown, 2014). Moreover, the principles of Communicative Language Teaching highlight the role of authentic material in language learning (Chambers, 1997). The appealing examples 
of authentic use of the newly learned words in video clips, songs, TV shows, etc. can also make vocabulary learning an entertaining and enjoyable process. Hence, the original content provided in WordUp can promote vocabulary learning. Additionally, WordUp is programmed to repeatedly expose students to the words they have learned. The frequency of this repetition is determined by the number of times that the users answer correctly to questions regarding the meaning of the previously learned vocabulary. Nation (2001) stated that the repetition of words through the reminding process is proven to facilitate users' memorisation of the words up to a great extent. Unfortunately, this application does not provide learners with activities in which the learners can use the words and make sentences or do tasks using the words. In other words, we assume there is a need for more practices and exercises through which the users can utilise and work with the learned material.

In order to make a better judgement regarding the efficiency of WordUp, a group of EFL learners, including five at elementary level and seven at intermediate level, were asked to use this application over a 2-week period and report their opinion about their experience to the researchers. In return for their participation, the researchers provided the learners with free instruction on their language problems during the 2 weeks. Seven students (three elementary and six intermediate) commented that WordUp can successfully engage learners in the process of vocabulary learning because of the authentic and in some cases "entertaining" examples. Furthermore, almost all of the learners believed that the dictionary entries presented in the app made it easier for them to use the app. On that issue, one of the learners (intermediate) stated:

I do not like working with apps that do not provide me with the meaning of new words because then I have to leave the app and look up a word in some other dictionary before I can proceed their vocabulary lesson.

Nonetheless, some students, three of the elementary level students and one at intermediate level, found the examples difficult to understand since they contained words which were not familiar for the users.

\section{Conclusion}

WordUp intends to foster its users' English vocabulary learning through extensive exposure to new words being used in authentic contexts. This application places the learners at an appropriate level and presents them with some new words from its 25,000 of most frequently used English words, which are grouped to the first most useful thousand words, to the 25th mostly used thousand words. The most significant features of this application are its thorough list of authentic examples and efficient method of reminding the words to the learners. However, more engaging practices and exercises which gives the users opportunities to apply the words in sentences uttered by themselves could help with the learning process and avoid mere storing of the words as the learners' passive knowledge (Ur, 2012). In addition, a topic-based categorisation of the words could enhance the efficiency of this application. All in all, WordUp can be a useful tool for English learners at all levels above A1 (CEFR) to work on their vocabulary knowledge outside of the class and get familiar with different uses of the words in various authentic 
contexts. In order to maximise the effect of this application, teachers can introduce further practices on using the words by the students through their productive skills. In the absence of a teacher, the least the learners can do is writing sentences and texts containing the words they acquire on WordUp every day.

\section{References}

Block, C. C., \& Fitzgerald, J. J. (2006). The new look for research-based best practice. In C. C. Block \& J. N. Mangieri (Eds.), The vocabulary-enriched classroom: Practices for improving the reading performance of all students in grades 3 and up (pp. 8-17). Scholastic.

Brown, H. D. (2014). Principles of language learning and teaching (6th ed.). Pearson Education.

Chambers, F. (1997). What do we mean by fluency? System, 25(4), 535-544. https:// doi.org/10.1016/S0346-251X(97)00046-8

Cunningham, P. M. (2009). What really matters in vocabulary: Research-based practices across the curriculum. Pearson.

Fan, N. (2020). Strategy use in second language vocabulary learning and its relationships with the breadth and depth of vocabulary knowledge: A structural equation modeling study. Frontiers in Psychology, 11(752), 1-14. https://doi. org/10.3389/fpsyg.2020.00752

Giampieri, P. (2019). The web as corpus in ESL classes: A case study. International Journal of Language Studies, 13(2), 91-108.

Gilmore, A. (2007). Authentic materials and authenticity in foreign language learning. Language Teaching, 40(2), 97-118. https://doi.org/10.1017/ S0261444807004144

Lewis, M. (1993). The lexical approach: The state of ELT and a way forward. Language Teaching Publications.

Lin, J. J., \& Lin, H. (2019). Mobile-assisted ESL/EFL vocabulary learning: A systematic review and meta-analysis. Computer Assisted Language Learning, 32(8), 878-919. https://doi.org/10.1080/09588221.2018.1541359

Mills, D. (2000). Web-based technology as a resource for form-focused language learning. TESOL Quarterly, 34(3), 603-615. https://doi.org/10.2307/3587749

Mizumoto, A., \& Takeuchi, O. (2009). Examining the effectiveness of explicit instruction of vocabulary learning strategies with Japanese EFL university students. Language Teaching Research, 13(4), 425-449. https://doi.org/10.1177/1362168809341511

McCarthy, M. (1990). Language teaching: A scheme for teacher education. Oxford University Press.

Moir, J., \& Nation, I. S. P. (2002). Learners' use of strategies for effective vocabulary learning. Prospect Journal, 17(1), 15-35.

Nakata, T. (2015). Effects of expanding and equal spacing on second language vocabulary learning: Does gradually increasing spacing increase vocabulary learning? Studies in Second Language Acquisition, 37(4), 677-711. https://doi. org/10.1017/S0272263114000825 
Namaziandost, E., Razmi, M. H., Ahmad Tilwani, S., \& Pourhosein Gilakjani, A. (2021). The impact of authentic materials on reading comprehension, motivation, and anxiety among Iranian male EFL learners. Reading \& Writing Quarterly, 38, 1-38. https://doi.org/10.1080/10573569.2021.1892001

Nation, I. S. P. (2001). Learning vocabulary in another language. Cambridge University Press. https://doi.org/10.1017/CBO9781139524759

Nation, I. S. P. (2013). Learning vocabulary in another language (2nd ed.). Cambridge University Press.

Nunan, D. (1988). The learner-centered curriculum. Cambridge University Press.

Nushi, M., \& Jenabzadeh, H. (2016). Teaching and learning academic vocabulary. California Linguistic Notes, 40(2), 51-70.

Peacock, M. (1997). The effect of authentic materials on the motivation of EFL learners. ELT Journal, 51(2), 144-156. https://doi.org/10.1093/elt/51.2.144

Römer, U. (2011). Corpus research applications in second language teaching. Annual Review of Applied Linguistics, 31, 205-225. https://doi.org/10.1017/ S0267190511000055

Schmitt, N. (2000). Vocabulary in language teaching. Cambridge University Press.

Taka, V. (2008). Vocabulary learning strategies and foreign language acquisition. Multilingual Matters. https://doi.org/10.21832/9781847690401

Thornbury, S. (2000). A dogma for EFL. IATEFL Issues, 153(2), 59-67.

Ur, P. (2012). A course in English language teaching. Cambridge University Press.

Zhang, H. (2020). Testing reciprocity between lexical knowledge and reading comprehension among Chinese children: A cross-lagged panel analysis. European Journal of Psychology of Education, 35(2), 1-20. https://doi.org/10.1007/ s10212-020-00462-9 